\title{
O ceticismo antifideísta de Hume
}

\author{
Hume's antifideistic skepticism
}

\section{Rafael Bittencourt Santos}

Doutorando em filosofia pela UFRGS

Resumo: O ceticismo de Hume pode parecer próximo do fideísmo cético em virtude da sua crítica às faculdades humanas envolvidas no conhecimento da verdade e da sua defesa da necessidade de um mecanismo não racional como fundamento das nossas crenças. A diferença entre ambos estaria na identificação da solução para a suspensão do juízo resultante da descoberta da insuficiência da razão para compreender o mundo e guiar a ação: um apontaria para a determinação natural, outro, para a Revelação. Argumento aqui que essa proximidade não é mais do que aparente. A filosofia de Hume constitui-se como antifideísta não apenas por razões prudenciais, práticas ou pragmáticas, mas também pelos seus fundamentos filosóficos. Para mostrá-lo, examino a discussão entre Dêmeas e Filão nos Diálogos sobre a Religião Natural, a investigação sobre a origem da religião na História Natural da Religião e as razões para a recomendação da filosofia ante a superstição no Tratado da Natureza Humana.

Palavras-chave: Ceticismo; Fideísmo; Misticismo; Empirismo; Hume.

Abstract: Hume's skepticism may seem close to skeptical fideism in view of his critique of human faculties involved in the knowledge of truth and his defense of the need for a non-rational mechanism as foundation of our beliefs. The difference between them would lie in the identification of the solution to the suspension of judgment resul- 
ting from the discovery of the insufficiency of reason to understand the world and to guide action: one would point to natural determination, another to Revelation. I argue here that this closeness is no more than apparent. Hume's philosophy is constituted as antifideist not only for prudential, practical or pragmatic reasons, but also for its philosophical foundations. To show it, I examine the discussion between Demea and Philo in the Dialogues Concerning Natural Religion, the investigation into the origin of religion in the Natural History of Religion and the reasons for the recommendation of philosophy to superstition in the Treatise of Human Nature.

Keywords: Skepticism; Fideism; Mysticism; Empiricism; Hume.

\section{Introdução}

A o final do Livro 1 do Tratado da Natureza Humana, Hume Aafirma que "o verdadeiro cético desconfiará tanto de suas dúvidas filosóficas como de sua convicção filosófica" (TNH 1.4.7.14 ${ }^{107}$ ). Isso, que pode parecer mera recomendação de prudência, é parte de uma disputa a respeito da natureza do ceticismo. No parágrafo imediatamente anterior, ele defende que a nossa curiosidade e ambição não devem nos levar para o caminho da superstição, e sim da filosofia, mais branda, moderada e até mesmo mais inofensiva que aquela (TNH 1.4.7.13). Devemos ver, nesse contexto, o supersticioso não somente como aquele que ignora a prudência filosófica, mas também como aquele que se apropria dos instrumentos da filosofia para subordiná-la à teologia ou à religião. Em especial, ele apropriase dos argumentos levantados pelo cético para mostrar a insuficiência da razão para tratar dos assuntos humanos, teóricos ou práticos, pretendendo mostrar que ela não pode ser a mestra das nossas vidas.

A crítica de Hume aos cartesianos e também aos empiristas que o antecedem é amplamente discutida. Nesse contexto, explica-se a sua crítica como uma crítica da razão em defesa do hábito ou da imaginação (Kemp Smith, 1905, p. 150; Stroud,

107 Referência ao Tratado da Natureza Humana, livro, parte, seção e parágrafo. 
1977, p. 14; Wright, 1983, p. 230), ou mesmo como uma condenação da pretensão de conhecer, simplesmente (Green, 1885, p. 2; Popkin, 1951, p. 387; Fogelin, 2009, p. 137). Contudo, essa crítica da razão não pode ser similar àquela promovida pelos místicos ou apologetas da fé bíblica. Esse é um ponto polêmico, pois há quem defenda tal proximidade ou similaridade (Zimmerman, 2008; Fogelin, 2017, p. 109). Além disso, essa proximidade é consequência, ainda que não declarada, de algumas leituras bem estabelecidas da filosofia de Hume, a saber, aquelas que assumem que o seu ceticismo é fruto da sua descoberta de uma contradição na razão ou na imaginação (Fogelin, 2009, p. 100; Fieser, 1989, p. 95; Maia Neto, 1991, p. 48).

A similaridade entre o ceticismo defendido por Hume e aquele promovido pelos místicos ou fideístas não é mais do que aparente. $\mathrm{O}$ ceticismo de Hume é também um ataque ao misticismo ${ }^{108}$. Eles não se distinguem meramente pelas consequências irreligiosas de um e religiosas de outro — isto é, não se diferenciam apenas pela orientação pretendida pelos seus defensores - mas também pelas suas premissas. O ceticismo de Hume não prescinde da confiança na razão, compreendida de modo lato como a capacidade dos homens de distinguir o verdadeiro do falso. Mais do que isso, ele combate o repúdio à razão promovido pelo fideísmo cético, um falso ceticismo a partir de uma perspectiva humiana ${ }^{109}$.

Para mostrá-lo, analisarei a disputa de Filão e Dêmeas ${ }^{110}$ nos Diálogos sobre a Religião Natural, em que tomo este como o

\footnotetext{
108 Isso vai ao encontro da posição de Penelhum (1983, p. 139), para quem a retórica fideísta de Hume é utilizada contra a fé.

109 Nesse sentido, minha proposta vai além da recentemente apresentada por Ferraz, que percebe a aparente proximidade da posição de Hume à posição fideísta (2016, p. 111) e a nega em virtude da proposta secularista de Hume (2016, p. 113) (na linha da interpretação do Tratado desenvolvida por Russell (ver 2008, cap. 17)) e de sua crítica à prática religiosa (Ferraz, 2016, p. 114). O que planejo negar é precisamente o que Ferraz concede, a saber, a "admissibilidade teórica ou filosófica" do fideísmo à luz da filosofia de Hume (2016, p. 114).

$110 \quad$ A respeito da grafia dos nomes das personagens dos Diálogos sobre a Religião Natural, adotei aquela utilizada pela tradução que utilizo nesse texto (a de Bruna Frascolla, referenciada ao final).
} 
representante do misticismo e aquele do ceticismo humiano. $\mathrm{O}$ seu desacordo a respeito das consequências das dúvidas céticas revela a sua distância: enquanto um ajusta a crença à razão, o outro defende a crença em detrimento da razão. A estratégia de Filão - a manipulação - indica o seu desacato à dignidade filosófica da posição de Dêmeas. As razões para tanto ficam mais claras à luz da História Natural da Religião, em que o misticismo torna-se caso de estudo empírico, não de discussão racional. Sua origem deve-se a tendências da natureza humana que podem ser compreendidas a partir de uma perspectiva exclusivamente causal. É possível compreender a sua origem e força, mas não defendê-lo. Para reforçar essa posição, recorro ao sistema filosófico apresentado no Tratado da Natureza Humana, em que o papel reservado à experiência implica a recusa do misticismo.

\section{Os Diálogos sobre a Religião Natural e o enfrenta- mento indireto do misticismo}

Uma aparente aliança entre Filão e Dêmeas começa a partir de uma breve disputa sobre o lugar da teologia na educação dos jovens: quando interpelado por Filão de que colocar a teologia como a última etapa no programa educacional poderia levar à sua rejeição, Dêmeas afirma que é apenas "enquanto uma ciência", isto é, enquanto "sujeita ao raciocínio humano e disputa", que ele posterga o ensino da teologia (DRN 1.2 $2^{111}$ ). A arrogância filosófica deveria ser combatida com o exame prévio das demais ciências, que mostraria o clima de disputa e incerteza que domina todos os empreendimentos humanos que pretendem derivar princípios a partir da razão. Assim, o aluno ficaria imune às tentativas dos filósofos de resolverem as disputas teológicas e poderia enfim ser apresentado aos "mistérios da religião". Filão, por sua vez, nota que Dêmeas tira vantagem dos princípios da filosofia, que "inspirando orgulho e autossuficiência, têm em todas as eras se achado tão destrutivos para os princípios de religião" (DRN 1.3), e concorda que quando a ignorância, "o remédio mais seguro", não é mais uma via possível para evitar a irreligiosidade, "os princípios de Dêmeas"

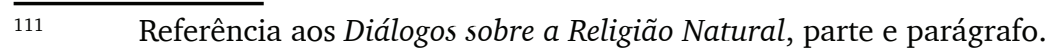


devem ser "aprimorados e cultivados", alegando que devemos nos tornar "completamente cônscios da fraqueza, da cegueira e dos limites estreitos da razão humana" (DRN 1.3).

A sua aliança se estabelece no enfrentamento a Cleantes. A posição de Cleantes, em defesa da qual evoca Locke, é a de que "a fé não é nada senão uma espécie de razão" (DRN 1.17 - grifos do original). Para Locke, a palavra revelada não é um caminho exclusivo para o conhecimento de determinadas verdades. Não há verdade revelada que não possa ser descoberta a partir da experiência e do raciocínio (Ensaio 4.18.4 ${ }^{112}$ ) nem pode ser o caso que a Revelação possa ir de encontro ao conhecimento (Ensaio 4.18.5). A proposição que contradiz o nosso conhecimento teria "sempre pendente esta objeção: que não saberíamos explicar como seja possível vir de Deus, o generoso Autor do nosso ser, algo que, se recebido por verdadeiro, destruirá completamente a parte mais excelente da sua obra, o nosso entendimento, [...]" (Ensaio 4.18.5). Da perspectiva apresentada por Dêmeas, Cleantes adota a arrogância filosófica da qual o discípulo deveria ser, pela sua educação, afastado. Os argumentos céticos aparecem como instrumentos úteis para o combate a essa arrogância.

A quase totalidade dos Diálogos avança a partir da argumentação conjunta de Filão e Dêmeas contra Cleantes. Posto que Filão é quem se expõe mais, é Dêmeas em geral quem toma a dianteira. Isso acontece no debate inaugural sobre o método de ensino (DRN 1.1), sobre a natureza de Deus (DRN $2.1 / 3.10$ ), sobre o antropomorfismo de Cleantes (DRN 4.2), sobre a fragilidade do método experimental (DRN 6.1) e sobre a miséria e o medo como a origem de fato da religião (DRN 10.1). Cabe notar que Filão nunca se opõe diretamente a Dêmeas, a não ser na discussão sobre o argumento a priori para a existência de Deus (DRN 9.10) — ponto que se revela pouco caro a Dêmeas (ver Dye (1989, p. 122/136)) e em que a sua argumentação parece ser destinada antes a Cleantes (ver Dye (1989, p. 133-134)) — e na conclusão da exposição do problema do mal, ápice da sua argumentação e momento em

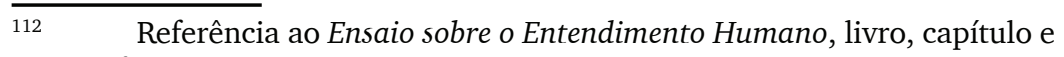
parágrafo. 
que Dêmeas retira-se do diálogo (DRN 11.17-21). À exceção desses dois momentos, Filão segue a brecha que Dêmeas abre na exposição de Cleantes ou abre uma via alternativa que não afronta (ao menos explicitamente) a posição de Dêmeas. Quando Dêmeas interroga Filão, nas partes 7 e 8, não o faz como se disputasse a tese de Filão (diferentemente de Cleantes), e sim como um pedido por maior esclarecimento.

A proximidade entre Filão e Dêmeas é aparente e, na obra, parte da estratégia argumentativa daquele contra este. À parte a revelação, ao final, das consequências ímpias que Filão retira das posições que assumiu conjuntamente com Dêmeas (DRN 11.17-21) e das oportunidades recém-notadas em que Filão aproveita a iniciativa de Dêmeas, pode-se observar que Filão não utiliza contra Dêmeas a acusação de obscuridade, que usa contra Cleantes (DRN 5.9). Além disso, a sua crítica aberta a Dêmeas surge somente após a saída deste da discussão: atente-se para a sua admissão de aversão ao misticismo (DRN 12.9/15-20) e para a admissão da razoabilidade da posição de Cleantes (DRN 12.2-3). Seja um recurso autoral para disfarçar o caráter irreligioso da obra (ver Monteiro, 2009, p. 137/149150/165-170), seja uma admissão sincera de que as posições de Filão são inconveniências insuficientes para abandonar a posição defendida por Cleantes (ver Tweyman, 1986, p. 127-132; Gaskin, 1988, p. 130) ${ }^{113}$, é significativo que isso seja feito na ausência de Dêmeas.

Dêmeas representa um desafio específico para argumentação filosófica porque não toma uma contradição como evidência de um erro em um sistema de pensamento (ou, pelo menos, no seu sistema). Os mistérios da Criação não estão para além da compreensão humana porque exigem informações das quais não dispomos, e sim porque não se encaixam com as informações de que dispomos. Tenhamos a conclusão de Malezieu sobre uma suposta contradição da Geometria:

$113 \quad$ Aqui, deve-se compreender a posição de Cleantes reduzida à tese de que a observação do mundo deve nos impactar de modo a fazer surgir a crença em uma causa inteligente para o mundo, não ao seu desenvolvimento da analogia entre o mundo e um artefato. 
Eis a nossa razão reduzida a extremos incompreensíveis. A Geometria nos demonstra a divisibilidade da matéria ao infinito e nos mostra simultaneamente que ela é composta de indivisíveis. Humilhemo-nos uma vez mais e reconheçamos que não é próprio a uma criatura, seja qual for a excelência que ela possa ter, pretender conciliar as verdades cuja compatibilidade o Criador quis the ocultar. (Malezieu, 2005, p. 342 - tradução minha)

Percebamos a atitude semelhante no discurso de Dêmeas de humilhação, rebaixamento e desautorização da razão diante dos mistérios divinos.

Criaturas finitas, fracas e cegas, devemos nos humilhar perante sua augusta presença e, conscientes de nossas fraquezas, adorar em silêncio suas perfeições infinitas que o olho não viu, a orelha não ouviu e tampouco adentrou o coração do homem conceber. Elas estão encobertas numa nuvem profunda para curiosidade humana: é profanidade tentar penetrar essas obscuridades sagradas; e próxima à impiedade de negar sua existência é a temeridade de intrometer-se em sua natureza e essência, decretos e atributos. (DRN 2.1)

A estratégia de Cleantes diante de Dêmeas é de afronta direta. Tomando um tópico particular, a natureza da mente divina, vejamos a resposta de Cleantes após Dêmeas apresentar a mente divina como tendo propriedades que parecem evidentemente incompatíveis.

\begin{abstract}
"Posso admitir prontamente", disse Cleantes, "que aqueles que mantêm a simplicidade perfeita do Ser supremo na extensão em que a explicaste são místicos completos e acusáveis de todas as consequências que tirei de sua opinião. São, numa palavra, ateus sem saber disto. Pois embora se admita que a Deidade possua atributos dos quais não temos compreensão, ainda assim jamais devemos lhe imputar quaisquer atributos que sejam incompatíveis com aquela natureza inteligente que lhe é essencial. Uma mente cujos atos, sentimentos e ideias não são distintos e sucessivos, que é inteiramente simples, totalmente imutável, é uma mente que não tem nenhum pensamento, nenhuma razão, nenhuma vontade, nenhum sentimento, nenhum amor, nenhum ódio - ou, numa palavra, não é nenhuma mente. É um abuso de termos dar a isto esta designação, e podemos tão bem falar de extensão limitada sem figura ou de número sem composição." (DRN 4.3 - itálicos do original)
\end{abstract}

A tentativa de Cleantes de requerer de Dêmeas respeito aos significados comuns das palavras e às noções mínimas de compreensibilidade é vã. Para Dêmeas, a dimensão lógica 
ou argumentativa do discurso tem um caráter secundário nos assuntos teológicos. Evidência disso é a sua falta de insistência na defesa do argumento a priori para a existência de Deus, que professou como o mais vantajoso (DRN 9.1), aceitando prontamente a tese de Filão de que a religião tem uma origem diversa que a do argumento a priori (DRN 9.11). O que seria uma condenação da religião como infundada (uma vez que tanto o argumento a priori como o a posteriori teriam sido mostrados insuficientes para estabelecer a existência de Deus) é, para Dêmeas, evidência de que é apenas contraproducente querer raciocinar a respeito desses tópicos.

O movimento de Filão é mais sutil.

[Fala de Filão] Sabedoria, pensamento, desígnio, conhecimento: estas lhe [ao ser Divino] atribuímos com justeza porque essas palavras são honoráveis entre homens e não temos outra língua ou outras concepções pelas quais possamos expressar nossa adoração por ele. Mas vamos nos precaver para não pensar que nossas ideias dalgum modo correspondem às suas perfeições ou que seus atributos têm alguma semelhança com essas qualidades entre homens. Ele é infinitamente superior a nossa visão e compreensão limitadas, e é mais objeto de adoração no templo de que disputa nas escolas. (DRN 2.3)

Filão concorda com Dêmeas que a predicação dos atributos de Deus é metafórica e não revela nada a respeito da sua natureza. Contudo, essa impossibilidade de conhecimento implicará a indefensibilidade da criação divina diante da aparente imperfeição da sua obra.

[Fala de Filão] Tem-se, penso eu, que admitir que, caso uma inteligência limitadíssima, à qual supomos que o universo seja maximamente estranho, estivesse bem segura de que este é a produção dum Ser boníssimo, sapientíssimo e poderosíssimo porém finito, ela formaria de antemão por suas conjecturas uma noção do mundo diferente daquilo que por experiência o vemos ser. E jamais imaginaria, meramente a partir daqueles atributos da causa do qual fora informada, que o efeito pudesse ser tão cheio de vício, miséria e desordem como aparece nessa vida. Supondo agora que esta pessoa fosse trazida ao mundo ainda segura de que este é a obra de tal Ser sublime e benevolente, ela poderá, talvez, se surpreender com o desapontamento, mas nunca renunciaria à sua crença anterior se esta for fundada nalgum argumento bem sólido, já que uma inteligência tão limitada deve estar cônscia de sua cegueira e ignorância e tem de admitir que pode haver para tais problemas muitas soluções que 
sempre escaparão à sua compreensão. Mas supondo - o que é o real caso do homem -, que esta criatura não esteja anteriormente convencida duma inteligência suprema benevolente e poderosa, mas fique livre para colher tal crença pelas aparências: altera-se completamente o caso, e ela não achará qualquer razão para tal conclusão. Poderá estar plenamente convencida dos limites estreitos do seu entendimento, mas isto não lhe ajudará a formar uma inferência concernente à bondade dos poderes superiores, pois tem que formá-la a partir daquilo que conhece, não daquilo que ignora. (DRN 11.2 - itálico do original)

Ignorarei, aqui, a qualificação da divindade como finita, fruto de um movimento de Cleantes em defesa da inteligibilidade da natureza e da obra divinas. Interessa-me notar o rumo distinto que Filão dá ao apelo à ignorância humana daquele esperado por Dêmeas. Tendo o argumento $a$ priori para a existência de Deus - o proposto por Dêmeas - falhado em passar no crivo das personagens (DRN 9.4-11) bem como o argumento a posteriori, pelo menos no de Dêmeas (DRN 9.1), a condição que nos permitiria considerar o mundo fruto de uma inteligência benevolente e poderosa não é realizada. Com isso, a conclusão de que a natureza divina é boa e perfeita fica interditada.

Considere-se que não é uma alternativa aberta nesse cenário tomar Deus como não sendo perfeito nem como não sendo bom - considerá-lo, como chega a fazer Filão, como desprovido de atributos morais (DRN 11.16) é máxima impiedade (DRN 11.18) (sobre isso, cabe ver Russell (2008, p. 184-186)). Considere-se também que o propósito de Filão não é provar a incompatibilidade do mundo com a perfeição e benevolência divinas, e sim a impossibilidade de inferi-las a partir daquilo que conhecemos. Ao fazê-lo, Filão conduz o ceticismo inicial de Dêmeas à conclusão de que não podemos dizer, de Deus, que ele é bom nem perfeito, uma conclusão ímpia que Dêmeas não pode aceitar.

Evidentemente, isso não esgota o assunto e alguém com a posição de Dêmeas, na hipótese de que Filão conduziu com sucesso a sua argumentação, poderia se utilizar de outros recursos para defender-se. O caso aqui não é avaliar inteiramente a extensão da discussão nem os limites dos Diálogos, e sim a es- 
tratégia de Filão para desarmá-lo no campo filosófico, no qual Dêmeas aceitou entrar (ver DRN 2.2).

Ao marginalizar o argumento a priori, Dêmeas assume a posição de que a religião é ou deve ser adotada em virtude de uma espécie de necessidade prática. A providência divina daria alguma esperança de felicidade e proteção nessa vida (DRN 10.1) bem como seria aquilo que manteria os seres humanos apegados à vida (DRN 10.17). Filão rebate essas considerações, afirmando que a esperança em uma providência futura não afeta de modo concreto as ações humanas (DRN 12.13), a não ser de modo negativo (DRN 12.19) (como os demais ataques diretos de Filão à posição de Dêmeas, isso é feito na sua ausência).

A estratégia de Filão é enunciada às claras após a retirada de Dêmeas. "Mas em proporção à minha veneração à religião verdadeira está a minha abominação às superstições vulgares, e sinto um prazer peculiar, confesso, em empurrar tais princípios às vezes para a absurdidade, às vezes para a impiedade" (DRN 12.9). Se considerarmos a absurdidade como aquilo que é contraditório ou sem sentido, isso não funciona diante de um adversário como Dêmeas. A impiedade, por sua vez, é algo com o qual ele se preocupa e se importa em evitar.

A postura de Filão, diante da ignorância, é de recusar a afirmação de qualquer posição a respeito daquilo que é ignorado (DRN 1.3). Dêmeas, por sua vez, o utiliza para desautorizar a recusa dos mistérios da religião em virtude do estranhamento diante da sua alegada incompreensibilidade (DRN 1.2).

A esse respeito, Cleantes e Filão se revelam mais próximos entre si do que com Dêmeas. Embora discordem a respeito da força do argumento a posteriori para a existência de Deus, ambos concordam com a necessidade de restringir os raciocínios sobre questões de fato ao que a experiência permite, abdicando dos demais juízos. A disputa inicial sobre o ceticismo entre Cleantes e Filão serve mais a uma falsa aproximação entre este e Dêmeas do que para revelar a verdadeira disputa entre os dois primeiros, a saber, o grau de perfeição da analogia entre o mundo e um artefato, base do argumento a posteriori apresentado por Cleantes (DRN 2.5). Com Cleantes, Filão pode 
argumentar honesta e diretamente, como acontece durante toda a obra, porque ambos estão comprometidos com o "bom senso natural", para usar uma expressão do próprio Cleantes (DRN 3.9). Dêmeas, por sua vez, não pode ser confrontado diretamente, porque abdica de falar com sentido sobre o tópico, e abandona a discussão ao perceber que sua própria posição o leva a uma situação embaraçosa (DRN 11.21).

\section{A História Natural da Religião e a origem corrup- ta da superstição}

O recurso à História Natural da Religião para criticar a posição de Dêmeas é um apelo a uma via psicologizante, que pretende explicar o misticismo a partir dos mecanismos causais que atuam nos seres humanos ${ }^{114}$. Se for o caso que o místico, como Dêmeas, não se vê limitado pela contradição ou o absurdo, pelo menos nos assuntos teológicos, é vã a tentativa de compreendê-lo a partir da sua dimensão lógica ou argumentativa. Pior ainda, a de tentar refutá-lo nessa mesma dimensão:

Opor-se à torrente da religião escolástica mediante máximas tão insignificantes como estas: "que é impossível a mesma coisa ser e não ser; que o todo é maior que a parte; que dois mais três são cinco", é pretender conter o oceano com juncos. Defendermos a profana razão contra os mistérios sagrados? Nenhuma punição é suficiente o bastante para a nossa impiedade. (HNR 11.5 ${ }^{115}$ )

Isso nos desloca da discussão com o místico para uma discussão sobre o místico, uma vez que ele não admite um diálogo franco - o que a estratégia retórica de Filão e o abandono de Dêmeas indicam. Isso também nos retira de um domínio

$114 \quad$ Minha proposta é análoga a de Guimarães, que toma a vitória intelectual de Filão nos Diálogos como algo que abre os horizontes para o estudo empírico da religião com o intuito de compreender a sua persistência nas mentes instruídas mesmo diante da sua falta de base (2013, p. 192), o qual é levado a cabo na História Natural da Religião. (isso também pode ser observado em Gaskin (1988, p. 183)) Ocorre que dou a Dêmeas mais relevância (para ela, sua a função seria a do "alívio cômico" (2013, p. 180)).

115 Referência à História Natural da Religião, seção e parágrafo, editada por Beauchamp (ver Hume, 2007). A tradução utilizada é a de Conte (ver Hume, 2004). 
exclusiva ou primordialmente argumentativo e nos leva para um domínio em que considerações factuais são mais relevantes. Sobre isso, ignorarei a veracidade das afirmações de Hume sobre os processos empíricos que atuam junto aos indivíduos levando-os à ojeriza à razão e me centrarei no modo como ele os utiliza para atacar o misticismo.

Na História Natural da Religião, o medo, considerado como a origem das primeiras ideias religiosas (HNR 2.4), explica as corrupções de algumas práticas e orientações religiosas. Aliado à pretensão de sistematização existente nas religiões monoteístas, leva à instrumentalização da filosofia (HNR 11.3) e, em última instância, ao combate ao bom senso (HNR 11.4).

A sua origem no medo é uma questão de fato: os eventos que perturbam a regularidade da natureza seriam os que mais chamariam a atenção dos homens no estágio inicial da sociedade (HNR 1.6). Incapazes de descobrir as causas dos desastres e males que os afetariam, transferir-lhes-iam qualidades humanas por uma espécie de tendência usual de antropomorfizar os fenômenos naturais (HNR 2.3).

Embora a evidência da existência de Deus estaria na uniformidade da natureza (HNR 6.2), seriam "as convulsões da natureza, as catástrofes, os prodígios e milagres", que em certa medida refutam "a ideia de um plano elaborado por um sábio diretor", aquelas que "imprimem nos homens os mais fortes sentimentos religiosos, pois as causas dos acontecimentos parecem, então, as mais obscuras e inexplicáveis" (HNR 6.3). Perceba-se a crítica direta desenvolvida dentro do campo religioso às causas originais da superstição: a violação da uniformidade da natureza, cerne do argumento a posteriori, que seria o único respeitável, enfraquece a convicção racional em um "sábio diretor".

Sendo o medo a causa principal da formação das crenças e práticas religiosas, a atribuição de qualquer limitação ou imperfeição à divindade é evitada pelo temor da sua represália (HNR 7.1). A isso, três fenômenos seguem-se: a insinceridade (HNR 7.1/12.15/13.6), a autodepreciação (HNR 10.2) e o demonismo (HNR 13.1/6). O primeiro surge na tentativa de evitar ofender a divindade por medo da sua vingança por não representá-la 
à altura. O segundo, da comparação da natureza ou condição humana diante de tão grande entidade (que não se poderia representar levianamente), que evidenciaria a nossa fragilidade e insignificância. O terceiro, da infiltração daquilo que usualmente consideraríamos sinal de malícia para a imagem da divindade. Não fosse a divindade sujeita à ira ou à vaidade, por exemplo, a insinceridade e a autodepreciação não se estabeleceriam ou não se manteriam com facilidade nas mentes supersticiosas.

A passagem para o monoteísmo é acompanhada por uma ascensão da intolerância. Enquanto as religiões politeístas admitem a existência de outros deuses além daqueles do panteão local - com isso, admitem práticas e explicações distintas - as religiões monoteístas, ao excluírem a possibilidade de quaisquer outras divindades, resumem a visão de mundo correta àquela determinada pelo seu deus (HNR 9.1).

A adoção de escrituras únicas e canônicas dá firmeza aos princípios e doutrinas monoteístas (HNR 12.17). Isso favorece o seu estabelecimento e compreensão como teoria especulativa, o que torna atraente a sua inspeção pela filosofia (HNR 11.3). Ocorre que essa inspeção transforma-se em domínio da teologia sobre a filosofia - sendo a doutrina admitida antecipadamente como verdadeira e incontestável, a filosofia não pode rejeitar as incoerências recebidas.

A convicção prévia na doutrina não é por si só suficiente para explicar o sequestro da filosofia. Hume compreende esse fenômeno como resultante de uma "espécie de propensão para o absurdo e para a contradição" (HNR 11.3). Essa propensão envolve um desejo de relação especial com a deidade. Ao supersticioso, aquilo que qualquer homem poderia concluir a partir do exercício da razão parece incapaz de estabelecer tal relação porque o torna mais um dentre os demais, não o destacando do resto aos olhos da divindade. Sendo aquilo que a razão determina ou comanda o que deve ser aceito ou feito por qualquer ser humano por ser um ser humano (ou por ser um ser racional), não se estaria fazendo mais do que a obrigação, o que não seria digno de um elogio ou de uma atenção da divindade. No âmbito moral, isso se revela em atos cujos fins são o sacrifício do próprio agente. 
Se ele [o supersticioso] devolve algo emprestado ou paga uma dívida, sua divindade não lhe deve obrigação nenhuma, pois tais atos de justiça são os que estava obrigado a cumprir e o que muitos teriam cumprido mesmo que não houvesse deus nenhum no mundo. Mas se ele jejua um dia ou dá a si mesmo uns bons açoites, isso tem, na sua opinião, uma relação direta com a assistência de Deus. (HNR 14.6)

No âmbito teórico, na propensão para a crença no absurdo.

Se essa teologia [a popular] não ultrapassasse a razão e o senso comum, suas doutrinas pareceriam demasiado simples e familiares. É preciso inevitavelmente suscitar o assombro, aparentar mistério, procurar as trevas e a obscuridade, bem como fornecer um fundamento para o mérito dos adeptos fiéis que desejam uma oportunidade para subjugar sua razão rebelde por meio da crença nos mais ininteligíveis sofismas. (HNR 11.3)

Pode-se dizer, ademais, que as atitudes de repúdio à razão convêm à autodepreciação resultante da exaltação do caráter grandioso da divindade. Em "Da dignidade ou baixeza da natureza humana", Hume identifica duas estratégias argumentativas usadas para depreciar a natureza humana: "fazendo uma representação injusta da situação e insistindo unicamente nas fraquezas da natureza humana" e "estabelecendo uma nova e misteriosa comparação entre o homem e os seres da mais perfeita sabedoria" (Hume, 1985, p. 82-83 ${ }^{116}$ ). A incapacidade de compreender os mistérios revela, na perspectiva supersticiosa, a pequenez humana diante do poder divino, que pode aquilo que ao homem parece impossível e exige dele aquilo que parece injustificável.

Se considerarmos a História Natural da Religião (sem pretender esgotá-la) como uma obra contra o misticismo e tivermos Dêmeas como o seu representante, ela ajusta-se à estratégia de Filão de levá-lo à impiedade. Ao fim, a superstição depende de uma concepção ímpia da divindade, como sujeita a paixões e preocupações similares às humanas, e moralmente perversa, porque exige atos injustificáveis (e que assim devem ser). Os elementos causais que compõem o fenômeno supersticioso não são mera história. Porquanto não haveria fundamen-

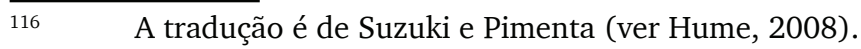


tação racional para a posição mística (o que seria mostrado nos Diálogos), a sua gênese factual é a sua sustentação.

Por fim, é interessante notar que a História Natural da Religião pode ser relacionada diretamente à discussão inaugural dos Diálogos sobre o programa educacional (que, segundo Clark (2013, p. 71), não é um tema secundário da obra). A valorização do absurdo e o ataque à razão não são apresentados somente como fenômenos espontâneos ou próprios dos indivíduos, mas também como fruto da perversidade dos sacerdotes.

Barbárie e arbitrariedade: essas são as qualidades, ainda que dissimuladas com outros nomes, que formam, como podemos observar universalmente, o caráter dominante da divindade nas religiões populares. E até os sacerdotes, em vez de corrigir essas ideias perversas dos homens, têm-se mostrado dispostos a alimentá-las e a encorajá-las. Quanto mais monstruosa é a imagem da divindade, mais os homens se tornam seus servidores dóceis e submissos, e quanto mais extravagantes são as provas que ela exige para nos conceder sua graça, mais necessário se faz que abandonemos nossa razão natural e nos entreguemos à condução e direção espiritual dos sacerdotes. (HNR 14.8 - grifos do original)

O projeto educacional de Dêmeas consiste em "temperar" as mentes dos jovens com a doutrinação enquanto aponta, no estudo das ciências, "a incerteza" e as "eternas disputas" que foram derivadas "da mera razão" para domar as "suas mentes para uma submissão apropriada e autodesconfiança" (DRN 1.2). Esse projeto, que não é contestado frontalmente por Filão ("Tua precaução", diz Filão, "em temperar as mentes de tuas crianças com piedade precoce é decerto muito razoável" (DRN 1.3)), identifica-se com a atitude dos sacerdotes mencionados. Dêmeas — e o místico — não é somente um adversário filosófico ou especulativo, é também um adversário político (a respeito disso, é interessante consultar Clark (2013, p. 70-73), que vê na intolerância de Dêmeas um aspecto importante dos Diálogos como uma obra política, bem como Garrett (2015, p. 287/292), que vê uma mensagem importante na relação entre Filão e Cleantes). 


\section{O Tratado da Natureza Humana e a recomenda- ção da filosofia}

O encerramento da História Natural da Religião aponta como antídoto à superstição a fuga para "as regiões calmas, ainda que obscuras, da filosofia" (HNR 15.13). Isso ecoa a última seção do Livro 1 do Tratado da Natureza Humana.

A superstição é certamente muito mais audaz em seus sistemas e hipóteses que a filosofia; enquanto esta se contenta em atribuir novas causas e princípios aos fenômenos que aparecem no mundo visível, aquela abre um mundo só seu, apresentando-nos cenas, seres e objetos inteiramente novos. Portanto, como é quase impossível para a mente humana permanecer, como a dos animais, dentro desse estreito círculo de objetos que formam o tema das conversas e ações cotidianas, o que temos a fazer é apenas deliberar sobre a escolha de nosso guia e dar nossa preferência àquele que é mais seguro e agradável. Quanto a isso, ouso recomendar a filosofia, e não hesito em escolhê-la à superstição, de qualquer gênero ou nome. (TNH 1.4.7.13)

Em que pesem as razões que podem tornar plausível atribuir a Hume um ceticismo teórico radical (na linha de Fogelin, 1985, p. 6), isto é, a posição de que nenhuma crença pode ser justificada, a crítica de Hume à superstição e a sua recomendação da filosofia requerem a admissão de algum critério objetivo para julgar crenças ou sistemas. Possa ou não esperar a verdade ou o conhecimento, o caso é que, sem tal parâmetro, Hume não está autorizado a apresentar a sua preferência pela filosofia como mais do que um capricho pessoal. Mesmo a sua declaração de que "os erros da religião são perigosos; os da filosofia, apenas ridículos" (TNH 1.4.7.13) precisa de algum suporte que não a mera afetação da natureza sobre si $^{117}$.

\footnotetext{
$117 \quad$ Pode-se ler o encerramento do Livro 1 do Tratado como uma espécie de romance filosófico em que Hume expõe o seu trajeto à filosofia, que não pode ser generalizado (ver Suzuki, 2011, p. 328). Mesmo que assim seja, essa é uma atitude similar a de Descartes no Discurso do Método, em que o seu raciocínio, embora apresentado como valendo unicamente para si (1902, p. 6), tem a pretensão de ser reconhecido como forçoso pelos demais. Aqui, deve-se distinguir o motivo do interesse do indivíduo pela filosofia (a curiosidade) da sua recomendação como superior à religião ou superstição para a satisfação desse interesse.
} 
$\mathrm{O}$ ataque de Hume à superstição difere do seu ataque ao ceticismo que propõe a suspensão total do juízo. Contra este, a sua teoria da crença é o seu instrumento. A impraticabilidade da suspensão do juízo impossibilita a admissibilidade desse tipo de ceticismo. O cético equivoca-se a respeito da natureza da crença ao tomá-la como podendo ser fruto de um processo exclusivamente racional quando elementos da nossa natureza sensível e passional precisam operar na sua formação (ver, por exemplo, Kemp Smith (1905, p. 165) e Popkin (1951, p. 394)).

A necessidade da crença nada mais determina do que isso: que precisamos crer e agir no mundo. "Como?" é a pergunta subsequente e aquela a respeito da qual a disputa com o místico ou supersticioso se dá. A identificação de crenças irresistíveis, isto é, crenças "às quais simplesmente não podemos recusar nosso assentimento" (Balieiro, 2016, p. 177) ${ }^{118}$, não basta se nada determina que devamos limitarmo-nos à irresistibilidade. Ademais, se a irresistibilidade for compreendida tão somente como um arrebatamento psicológico, nenhuma crítica pode ser feita ao místico convicto. Para dizer que ele confunde o que é necessário ou irresistível, é preciso sair da dimensão puramente causal.

Limitando-nos aos raciocínios causais, os mais importantes para os juízos a respeito de questões de fato e existência (segundo Hume (TNH 1.3.2.2)), podemos dizer que é a própria ideia de causação que fornece a base para sua normatização (ver Klaudat, 2005, p. 202). É central para a sua compreensão a suposição de uma conexão necessária entre a causa e o efeito

118 Também referidas como "crenças naturais" (ver Kemp Smith, 2005, p. 86 et seq./124 et seq.; Mounce, 1999, p. 43/53). Cabe notar que tanto a expressão "crença natural" como "crença irresistível" não são usadas por Hume: ele menciona princípios da natureza (TNH 1.3.16.9), princípios da natureza humana (TNH 1.4.4.2), instintos (TNH 1.3.16.9) e princípios irresistíveis (TNH 1.4.4.1). Aqui, há um passo interpretativo ao se avaliar as crenças resultantes de princípios naturais ou princípios irresistíveis como sendo elas mesmas naturais ou irresistíveis que não desenvolverei. É um exemplo a crença na existência em objetos materiais (ver TNH 1.4.2.1). Em princípio, nós continuaríamos a tê-la mesmo que um raciocínio mostrasse a sua falsidade (ver Popkin (1951, p. 394), Fogelin (1985, p. 11), Stroud (2006, p. 345-348) e Russell (2008, p. 177-180)). 
(TNH 1.3.2.11), cujo estabelecimento depende da percepção de uma conjunção constante entre a dita causa e o dito efeito (TNH 1.3.6.3). A atenção a esses dois elementos, a conexão necessária e a percepção da conjunção constante, é importante. Se ignorarmos a suposição de necessidade entre a causa e o efeito, tornamo-nos incapazes de diferenciar a causalidade da casualidade, isto é, um evento que ocorre após outro em virtude daquele e um evento que ocorre após outro sem relação com aquele (ou seja, por acaso). Se ignorarmos a percepção da conjunção constante, perdemos a base empírica das nossas inferências causais.

Podemos deixar de lado, aqui, a controvérsia metafísica sobre a natureza da causação: se a necessidade é estabelecida entre os objetos ou apenas na mente. Seja a necessidade causal uma relação real entre os objetos ou uma espécie de regularidade universal, importa notar que ela determina uma relação invariável entre a causa e o efeito. Por exemplo, quando um relógio atrasa, em vez de assumir uma irregularidade na operação das suas engrenagens, um relojoeiro pode supor que algo está as impedindo de funcionar corretamente, como um grão de poeira (esse exemplo é dado por Hume (TNH 1.3.12.5)). Ou seja, em vez de admitir a contingência da relação entre a causa e o efeito, ele supõe outras operações que a impedem de ocorrer.

Posto que uma conjunção constante entre dois objetos, qualquer que seja a sua regularidade e frequência, não garante que eles sejam causa e efeito um do outro, ela funciona como o fundamento empírico da inferência. O costume, o mecanismo que permite e força a inferência dos casos observados para os inobservados (ou seja, estabelece o juízo de que aqui há uma relação causal) (TNH 1.3.8.10), supre o que seria uma deficiência da razão humana e impede que possamos suspender o juízo. Sua função resume-se a possibilitar e determinar a crença (no quadro da presente discussão, a permitir a ação e barrar o cético). Para uma avaliação das crenças assumidas pelos indivíduos, é preciso retornar a atenção para o seu fundamento empírico - dado pela conjunção constante - e restrição conceitual - fornecido pela suposição de necessidade, que constitui 
a ideia de causação (a prioridade temporal da causa em relação ao efeito e a contiguidade de ambos também estabelecem restrições, mas que são secundárias para a presente discussão).

Para compreender como esse esquema funciona, examinemos o trato de Hume dos raciocínios prováveis. Por "raciocínios prováveis", tenhamos aqueles que tratam de questões de fato e são insuficientes para nos dar certeza. Hume distingue entre aqueles que nos levam à certeza (denomina-os "provas") e os que não o fazem para "preservar o significado comum das palavras e ao mesmo tempo marcar os diversos graus de evidência" (TNH 1.3.11.2). Isso porque "pareceria ridículo" "se alguém dissesse que é apenas provável que o sol nasça amanhã" (TNH 1.3.11.2).

A primeira distinção se dá entre as probabilidades de chances e as probabilidades de causas. Naquelas, nada leva a admitir uma situação futura mais provável do que outra. Tenhase o resultado do lançar de um dado de seis faces, sendo quatro marcadas de uma determinada maneira e duas, de outra (o exemplo é dado por Hume em TNH 1.3.11.6). Suponhamo-lo um dado não viciado, ou seja, a sua estrutura é tal que não privilegia a queda de uma das faces para baixo. Podemos dizer que é mais provável que a marcação presente nas quatro faces cairá voltada para cima meramente em virtude do seu maior número. Se fôssemos instados a apostar, essa seria a aposta mais razoável (ainda que, obviamente, incerta). Contudo, nada podemos determinar a respeito de qual face em particular cairá voltada para cima. Sobre isso, qualquer aposta seria mero palpite.

Nas probabilidades de causas, por sua vez, a experiência passada influencia o nosso juízo. Se na probabilidade de chances temos apenas um cômputo das possibilidades, na probabilidade de causas a experiência passada, com a influência do costume, leva-nos a considerar determinadas possibilidades mais prováveis que outras. Por exemplo, se um dado é mais pesado de um lado, podemos considerar mais provável que o lado oposto ficará voltado para cima. Aqui, a experiência passada faz com que nos inclinemos para uma das possibilidades em detrimento das demais. 
Note-se que mesmo a aplicação das probabilidades de chances requer determinações prévias a partir da experiência. Quando nos perguntamos sobre qual face de um dado não-viciado cairá para cima, consideramos que ele cairá, que é resistente o suficiente para não se espedaçar e assim por diante. Sem determinação alguma de causas, tudo é igualmente possível. O que é relevante é que, considerando tais determinações prévias, o resultado de alguns eventos nos é indeterminado.

Hume distingue três "probabilidades de causas": aquelas derivadas de uma experiência imperfeita, aquelas derivadas da operação de causas contrárias e aquelas formadas por analogia (TNH 1.3.12.25). A primeira decorre de uma experiência insuficiente para levar à certeza. O que seria uma experiência suficiente deve ser alvo de controvérsia e Hume não pretende resolvê-la (ver TNH 1.3.12.2). A título de exemplo: se eu não tenho como garantir a perfeita preparação de um determinado experimento, embora possa tomar o seu resultado como evidência de uma determinada relação de causa e efeito, não posso tomá-lo como determinante.

A segunda decorre da contrariedade de experiências. Aproveitando o exemplo do dado já oferecido: se sabemos que ele está viciado e tem uma face mais pesada, podemos considerar mais provável que ele cairá com a face mais pesada voltada para baixo. Não podemos considerar isso certo porque sabemos que não é sempre que isso acontece. Ambas as considerações dependem da observação passada e uma funciona como um contrapeso à outra.

Essa contrariedade das experiências leva a uma admissão da contingência das causas (hipótese do vulgo), isto é, que "mesmo sem encontrar nenhum obstáculo ou impedimento a sua operação, essas causas falhassem amiúde em sua influência habitual" (TNH 1.3.12.5), ou à suposição de uma "operação secreta de causas contrárias" (hipótese dos filósofos) (TNH 1.3.12.5). "Secreta", aqui, significa não-observada, e não inobservável. Não me delongarei na defesa de que Hume está, nesse caso, do lado dos filósofos. Aponto para a argumentação de Hume em defesa da prioridade temporal da causa em relação 
ao efeito, para a qual é central a admissão de que uma causa não pode existir sem produzir o seu efeito (ver TNH 1.3.2.7). Quando da contrariedade de experiências, o que ocorre é uma mensuração das experiências passadas análoga ao que ocorre na probabilidade de chances. Mas, em vez de cada possibilidade ser considerada igualmente, cada possibilidade ganha força conforme a sua presença na experiência passada.

Enquanto a probabilidade de causas baseada na contrariedade da experiência é afetada pelo grau de constância da experiência passada, a analogia é afetada pelo grau de semelhança entre os objetos do raciocínio. Na admissão de que "os casos de que não tivemos experiência devem se assemelhar aos casos de que tivemos experiência" (TNH 1.3.6.4) está não só a semelhança entre o observado e o inobservado, mas também a semelhança entre os próprios casos observados e inobservados. Quero dizer, os objetos observados em conjunção constante não precisam ser os mesmos. Operamos com critérios de semelhança para considerar a experiência passada. Quando fazemos inferências sobre seres humanos, consideramos a sua humanidade como critério de semelhança e desconsideramos as diferenças existentes entre os indivíduos. A rigor, toda inferência de causa e efeito envolve uma analogia. Ao destacá-la como um tipo de probabilidade, Hume aponta para outro fator além da constância da experiência passada que afeta a certeza do raciocínio causal. Quando há uma dessemelhança relevante entre os objetos considerados, não se pode ter certeza a respeito da inferência.

Ao lado das probabilidades já tratadas, Hume também avalia aquelas que ele denomina "não filosóficas", porque não foram admitidas como "fundamentos válidos de crença e opinião” pelos filósofos (TNH 1.3.13.1). Interessa, aqui, contrastá -las com as probabilidades filosóficas para esclarecer a função da experiência na fundamentação dos raciocínios causais.

O primeiro caso considerado por Hume é o da influência da distância no tempo de um evento na sua força em um argumento. "O argumento que fundamos sobre qualquer fato de que nos lembramos será mais ou menos convincente, con- 
forme o fato seja recente ou remoto" (TNH 1.3.13.1). O segundo caso é o da força da memória (TNH 1.3.13.2). Quanto mais forte uma lembrança, mais ela influenciará o juízo. O terceiro, a influência do tamanho da cadeia de raciocínio.

É certo que, quando se faz uma inferência imediatamente a partir de um objeto, sem qualquer causa ou efeito intermediário, a convicção é muito mais forte e a persuasão mais vívida do que quando a imaginação é conduzida por uma longa cadeia de argumentos conectados, por mais infalível que se considere a conexão entre cada elo e o seguinte. (TNH 1.3.13.3)

Por fim, o quarto caso é o que chamaríamos hoje de generalização apressada (ver TNH 1.3.13.7), uma formação indevida de regras gerais.

As probabilidades não filosóficas surgem do mesmo mecanismo que forma as probabilidades filosóficas, a saber, o costume. Ocorre que a inferência determinada pelo costume é influenciada pela força original das ideias (caso das duas primeiras probabilidades não filosóficas), tem sua operação desgastada quando a cadeia é longa demais (caso da terceira) e pode atuar de modo mais intenso ou ser influenciada por "circunstâncias supérfluas" (TNH 1.3.13.9) e levar-nos ao equívoco (caso da quarta).

Comecemos pelos três primeiros tipos. Sua inadequação é patente se atentarmos para a própria ideia de causação. Sendo a necessidade entre a causa e o efeito um dos seus componentes essenciais, a distância temporal e a fraqueza de nossa memória em nada devem afetar uma relação de causa e efeito, seja qual for a nossa compreensão da natureza dessa necessidade. A inversão feita por Hume sobre o fundamento do raciocínio causal, de que "em vez de a inferência depender da conexão necessária, é a conexão necessária que depende da inferência" (TNH 1.3.6.3), não implica um enfraquecimento da noção de necessidade. Isso seria descaracterizá-la, uma vez que a necessidade não admite gradação, porque não há um "meio-termo entre o acaso e a necessidade absoluta" (TNH 1.3.14.33). Se A causa B, a ocorrência de A deve ser suficiente para a ocorrência subsequente de $\mathrm{B}$, a menos que uma causa contrária intervenha (ver TNH 1.3.12.5 e 
TNH 1.3.15.8, a regra 6 para se julgar a partir de causas e efeitos) ou que A seja parte da causa de $\mathrm{B}$, não propriamente $a$ causa de $\mathrm{B}$ (ver TNH 1.3.2.7 e TNH 1.3.15.10, a regra 8 para se julgar a partir de causas e efeitos) ${ }^{119}$.

A quarta espécie de probabilidade não filosófica oferece um desafio diferente. Embora seja usual identificar a formulação do problema da indução por Hume no seu trato da fundamentação do princípio de que os casos não observados devem se assemelhar aos casos observados, seria mais adequado identificá-la no trato dessa probabilidade não filosófica. Ela oferece um problema genuíno à confiabilidade dos nossos raciocínios de causa e efeito, uma vez que ela não nos leva ao equívoco em virtude da infiltração de outro fator na experiência além da percepção de uma conjunção constante, como os anteriores. Se pensarmos no caso das probabilidades baseadas em uma experiência imperfeita, por exemplo, como as diferenciaríamos das generalizações apressadas? A esse respeito, parece que, no fim, é mediante o erro somente que se pode avançar ("Seguir regras gerais é uma espécie de probabilidade muito pouco filosófica. Entretanto, apenas se as seguimos podemos corrigir a esta e a todas as outras probabilidades não filosóficas" (TNH 1.3.13.12)).

De todo modo, cabe apontar a razão do erro. Afinal, não se pode explicar a falibilidade da generalização recorrendo exclusivamente à insuficiência de casos ou a um afobamento do espírito. Um único experimento pode ser suficiente para fundamentar uma inferência causal (Hume admite isso em TNH 1.3.12.3 e TNH 1.3.15.6 (regra 4)). O que ocorre na formula-

119 Pode-se falar em algo como uma noção forte ou fraca da conexão necessária pensando-se na disputa metafísica entre uma posição essencialista ou realista, que atribuiria às propriedades dos objetos o poder de causar, e uma posição regularista ou projetivista, que negaria ou suspenderia o juízo a respeito da existência de tal propriedade, tomando a nossa inferência causal como não mais que a afirmação de uma regularidade observada que esperamos que se mantenha. Minha argumentação independe da resolução dessa disputa. Mesmo uma interpretação regularista de Hume deve admitir que, diante de uma irregularidade que contrarie uma inferência causal que tenhamos feito previamente, ou atribuímos a irregularidade a um acontecimento que ignoramos ou admitimos um equívoco em nosso juízo prévio, agora corrigido à luz de nova evidência. 
ção da regra geral indevida é um equívoco quanto à semelhança entre os objetos do raciocínio. Ela é a aplicação inadequada da analogia (ver TNH 1.3.13.8). Por exemplo, seres humanos compartilham uma série de características entre si. Isso permite que possamos inferir que o efeito da ingestão de uma determinada substância por um grupo ocorrerá para os demais. Contudo, o efeito observado dessa substância pode se dever a uma peculiaridade desse grupo que não é compartilhada pelo conjunto dos seres humanos. O que se pretende que seja um juízo baseado na semelhança revela-se carente da semelhança apropriada.

O que está em jogo aqui não é a capacidade do indivíduo de corrigir a si mesmo no momento em que faz a inferência causal, isto é, não é uma busca pela infalibilidade do nosso raciocínio. É a inteligibilidade da relação causal. Se esta relação não é acidental - se podemos falar em juízos de causa e efeito que não são frutos de coincidências — o insucesso na sua identificação requer uma explicação. Isso envolve poder explicar por que as inferências que se revelaram incorretas foram incorretas, ainda que não parecessem.

Pode-se, por fim, pretender questionar a autoridade da experiência. Uma resposta completa nos desviaria demasiadamente do assunto. A suposição inicial de Hume parece ser a de que a experiência é o fundamento último das nossas crenças. $\mathrm{O}$ seu desafio é o de explicar o conhecimento humano sem precisar recorrer a conteúdos que não podem ser produzidos a partir dela. Isso posto, podemos circunscrever a questão à discriminação dos conteúdos que surgem a partir da experiência.

Segundo Miren Boehm,

A experiência cumpre uma função normativa na filosofia de Hume em virtude do fato de que a memória de conjunções constantes e impressões dos sentidos formam um sistema que a mente dignifica com o título de realidade, e ela faz isso porque a memória e os sentidos transmitem uma sensação de presentidade, porque eles são cridos, e porque eles afetam fortemente todas as operações da mente. (Boehm, 2013, p. 223 - tradução minha)

Boehm faz menção aos sistemas de realidades que Hume apresenta em TNH 1.3.9.3, em que as impressões e as ideias da 
memória compõem um sistema de realidade que, pela inferência causal, confere a mesma força aos objetos do juízo, fazendo com que os consideremos também reais. É a força com que as impressões (ou as ideias da memória ou as crenças) nos afetam que nos fazem considerá-las reais. Inquirir a respeito nos levaria no máximo a explicações fisiológicas do nosso funcionamento.

Cabe notar que a força que leva à crença não pode ser dissociada da sua fonte: as impressões e a memória, no primeiro sistema de realidade, e a inferência causal, no segundo. Isso porque se o título de realidade pudesse ser adquirido apenas em virtude da força sobre o espírito, precisaríamos considerar real aquilo que, por exemplo, tomamos como fruto da loucura, o que seria absurdo. Boehm aborda esse caso do seguinte modo:

No caso da loucura, a força e a vivacidade das ideias não derivam de uma conexão essencial com "as impressões da memória" ou a impressão presente, mas de uma "fermentação extraordinária do sangue e dos espíritos animais". Em um episódio de loucura, nós somos incapazes de distinguir crenças causais de "quimeras do cérebro". E "não há como distinguir entre a verdade e a falsidade". Por contraste, quando as ideias são avivadas pelo sistema dos sentidos e da memória, elas indicam a verdade ou realidade. (Boehm, 2013, p. 221 - tradução minha)

O indivíduo, admite-se, é incapaz de reconhecer a ilusão. Sem embargo, isso não significa a ausência de diferença entre a realidade e a ilusão. A menos que tomemos como fundamento da investigação uma perspectiva da primeira pessoa limitada, não estamos comprometidos com a identificação de um critério que qualquer indivíduo em qualquer situação deva reconhecer. ("Limitada" porque restringe o reconhecimento do que é real ao momento em que algo é percebido. Desconsidera-se a possibilidade de admissão posterior de engano). Assim como a crença nas probabilidades não filosóficas deve-se a uma transferência indevida de força, também a loucura resulta de um avivamento indevido de um determinado conteúdo da experiência.

Ao atentarmos para a experiência como aquilo que legitima os sistemas de realidades, qualificamos a função da irresistibilidade na determinação da necessidade da crença. Se aprofundarmo-nos no modo como devemos nos remeter à expe- 
riência, encontraremos uma complicada série de considerações a serem feitas. Afinal, não se pode considerar uma experiência isoladamente assim como não se pode considerar a experiência de um indivíduo isoladamente. Experiências passadas bem como experiências presentes podem ser reconsideradas em virtude da sua incompatibilidade com o resto do nosso sistema de realidades. Sem adentrarmos nessas considerações, ocorre que a irresistibilidade não determina por si só a legalidade de uma crença ou de um sistema de crenças.

Assim, a recomendação da filosofia em detrimento da superstição não é matéria exclusiva dos humores ou preferências pessoais de Hume, ela configura-se como uma declaração objetiva do modo adequado de saciar a curiosidade. A afirmação de que a superstição abre um mundo novo é a alegação de que ela ignora as limitações epistêmicas derivadas da correta atenção à experiência. Por sua vez, as "novas causas e princípios" identificadas pela filosofia são reorganizações das relações que estabelecemos entre os fenômenos observados, não um recurso a forças ou realidades ocultas que operam sobre o mundo.

\section{Considerações finais}

Pretendi ter mostrado como os Diálogos sobre a Religião Natural indicam a orientação distinta do ceticismo de Hume, representado por Filão, do ceticismo fideísta, encarnado por Dêmeas. Enquanto Filão restringe as suas conclusões àquilo que é permitido pela experiência e compromete-se com a inteligibilidade ou coerência dos conceitos com os quais trabalha, Dêmeas utiliza-se das conclusões céticas para livrar-se das amarras racionais e falar do que está para além do que podemos compreender. Essa atitude, que não pode ser enfrentada diretamente, o que também pretendo que possa ser inferido dos Diálogos, pode ser compreendida, embora não possa ser defendida de modo razoável. Essa conclusão pode ser inferida da História Natural da Religião.

No Tratado da Natureza Humana encontramos as bases teóricas tanto das posições assumidas por Filão como daquelas 
de natureza normativa ou avaliativa assumidas na História $\mathrm{Na}$ tural da Religião. A experiência funciona como limitadora do nosso conhecimento, negando a validade do salto de fé feito pelo místico. Ela também funciona como origem do nosso conhecimento, negando a validade da marginalização do critério de inteligibilidade dos conceitos que usamos. A crença, mesmo determinada pelo hábito, pode e deve ser avaliada a partir da sua origem. A impossibilidade da suspensão do juízo não leva à admissibilidade de qualquer juízo produzido pelo hábito. A irresistibilidade da crença ou de determinada crença não a isenta de poder ser examinada à luz da sua base empírica. A autoridade da experiência está na raiz da crítica de Hume ao misticismo ou de Filão a Dêmeas.

\section{Referências}

BALIEIRO, M. Filosofia e vida comum na epistemologia de Hume. In: CONTE, J.; FERRAZ, M.; ZIMMERMAN, F. (Org.). Ensaios sobre a filosofia de Hume. Florianópolis: NEL/UFSC, 2016. p. 159-182.

BOEHM, M. The Normativity of Experience and Causal Belief in Hume's Treatise. Hume Studies, vol. 39, n. 2, 2013. p. 203-231. Disponível em: https://doi.org/10.1353/hms.2014.0001. Acesso em 18/02/2019.

CLARK, S. Hume's Uses of Dialogue. Hume Studies, vol. 39, n. 1, (April) 2013. p. 61-76. Disponível em: https://doi.org/10.1353/ hms.2013.0005. Acesso em 18/02/2019.

DESCARTES, R. Oeuvres de Descartes, v. 6. Publieés par Adam \& Tannery. Paris: Léopold Cerf, 1902. Disponível em: http://philosophyfaculty.ucsd.edu/faculty/ctolley/texts/descartes.html. Acesso em 18/02/2019.

DYE, J. A Word on Behalf of Demea. Hume Studies, vol. XV, n. 1, (April) 1989. p. 120-140. Disponível em: http://www.humesociety. org/hs/issues/v15n1/dye/dye-v15n1.pdf. Acesso em 18/02/2019.

FERRAZ, M. C. O Status do Fideísmo na Crítica de Hume à Religião Natural. In: CONTE, J.; GUIMARÃES, L.; FERRAZ, M. C. (org). Ensaios sobre a filosofia de Hume. Florianópolis: NEL, 2016.

FIESER, J. Hume's Pyrrhonism: A Developmental Interpretation. Hume Studies, vol. XV, n. 1, (April) 1989. p. 93-119. Disponível em: http://www.humesociety.org/hs/issues/v15n1/feiser/fieser-v15n1. pdf. Acesso em 18/02/2019. 
FOGELIN, R. Hume's Presence in the Dialogues Concerning Natural Religion. Oxford: Oxford University Press, 2017.

FOGELIN, R. Hume's Skeptical Crisis. Oxford: Oxford University Press, 2009.

FOGELIN, R. Hume's Skepticism in the Treatise of Human Nature. London: Routledge \& Kegan Paul, 1985.

GARRETT, D. Hume. London: Routledge, 2015.

GASKIN, J. C. A. Hume's Philosophy of Religion. 2nd ed. London: Palgrave Macmillan UK, 1988.

GREEN, T. Philosophical Works, v. 1. London: Longmans, Greens, and CO, 1885.

GUIMARÃES, L. Retórica anticética nos Diálogos sobre a religião natural de Hume. Natureza Humana, vol. 15, n. 2, 2013. p. 174-193.

HUME, D. Da dignidade ou baixeza da natureza humana. In: HUME, David. A arte de escrever ensaio. Trad. Márcio Suzuki e Pedro Paulo Pimenta. São Paulo: Iluminuras, 2008.

HUME, D. Diálogos sobre a Religião Natural. Trad. Bruna Frascolla Salvador: EDUFBA, 2016.

HUME, D. A Dissertation on the Passions and The Natural History of Religion. Ed. by Tom Beauchamp. Oxford: Oxford Clarendon Press, 2007.

HUME, D. Essays Moral, Political, and Literary. Rev. ed. by E. F. Miller. Indianapolis: Liberty Classics, 1985.

HUME, D. História Natural da Religião. Trad. Jaimir Conte. São Paulo: Editora UNESP, 2005.

HUME, D. Tratado da Natureza Humana. Trad. Débora Danowski. $2^{\text {a }}$ ed. rev. e ampl. São Paulo: Editora Unesp, 2009.

KEMP SMITH, N. The Naturalism of Hume. Mind, New Series, vol. 14, n. 54, (April) 1905. p. 149-173.

KEMP SMITH, N. The Philosophy of David Hume with a new introduction by Don Garrett. New York: Palgrave Macmillan, 2005. First published: 1941.

KLAUDAT, A. Hume e a determinação da mente. In: GUIMARÃES, Lívia (Org). Ensaios sobre Hume. Belo Horizonte: Editora Segrac, 2005. p. 187-203.

LOCKE, J. Ensaio sobre o Entendimento Humano. Trad. Eduardo A. de Soveral. Lisboa: Fundação Calouste Gulbenkian, 1999.

MAIA NETO, J. R. Hume and Pascal: Pyrrhonism vs Nature. Hume Studies, vol XVII, n. 1, (April) 1991. p. 41-50. Disponível em: http:// www.humesociety.org/hs/issues/v17n1/neto/neto-v17n1.pdf. Acesso em $18 / 02 / 2019$. 
MALEZIEU, N. Elemens de Geometrie. In: KEMP SMITH, N. The Philosophy of David Hume with a new introduction by Don Garrett. New York: Palgrave Macmillan, 2005. p. 339-342.

MONTEIRO, J. P. Hume e a Epistemologia. São Paulo: Editora UNESP, 2009.

MOUNCE, H. O. Hume's Naturalism. London: Routledge, 1999.

PENELHUM, T. God and Skepticism: a Study in Skepticism and Fideism. Dordrecht: Springer Netherlands, 1983.

POPKIN, R. H. David Hume: His Pyrrhonism and His Critique of Pyrrhonism. The Philosophical Quarterly, vol 1. n. 5, (October) 1951. p. 385-407. Disponível em: http://www.jstor.org/stable/2216311. Acesso em 18/02/2019.

RUSSELL, p. The Riddle of Hume's Treatise. Oxford: Oxford University Press, 2008.

STROUD, B. The Constraints of Hume's Naturalism. Synthese, n. 152, 2006. p. 339-351. Disponível em: https://doi.org/10.1007/ s11229-006-9009-0. Acesso em 03/04/2019.

STROUD, B. Hume. London: Routledge, 1977.

SUZUKI, M. A aposta na filosofia. Kriterion, vol. 52, n. 124 (dezembro) 2011. p. 307-330. Disponível em: https://doi.org/10.1590/ S0100-512X2011000200004. Acesso em 18/02/2019.

TWEYMAN, S. Scepticism and Belief in Hume's Dialogues Concerning Natural Religion. Dordrecht: Spriger Netherlands, 1986.

WRIGHT, J. P. The Sceptical Realism of David Hume. Minneapolis: University of Minnesota Press, 1983.

ZIMMERMAN, F. Sobre o ceticismo acadêmico de Huet, Foucher e Hume. Cadernos Espinosanos, n. 18, 2008. p. 71-88. 